\title{
El Movimiento Natural de la Población
}

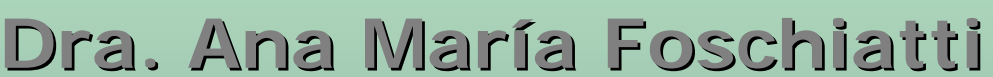


El estudio de la dinámica de la población (natalidad, mortalidad, nupcialidad y migraciones) constituye uno de los aspectos esenciales y más relevantes del análisis demográfico, pero a la vez es el más complejo en el plano metodológico

\section{DIFICULTADES}

- diversidad de fuentes necesarias y diversidad en la confección

- Amplitud de factores a tenerse en cuenta para su tratamiento - orden metodológico (cálculo de índices y tasas) 


\section{El crecimiento natural o movimiento natural o} vegetativo de la población es la variable demográfica que expresa la diferencia entre el número de nacimientos y el de defunciones de un área determinada en un período definido.

Positivo $\Rightarrow$ los nacimientos supera a las defunciones

Negativo $\Rightarrow$ mortalidad es mayor que la natalidad.

Este indicador muestra cómo evolucionaría la población si no hubiera migraciones. 


\section{Medición del Crecimiento Natural}

- Fuentes de información: Estadísticas Vitales

\section{Medición en números absolutos.}

$$
\mathbf{C N}=\mathbf{N}-\mathbf{D}
$$

Tasa de Crecimiento Natural

\section{TCN $=\underline{\text { CN (del Período) }} \times 100$ $\mathbf{N}^{\circ}$ medio de habitantes}




\section{DISTRIBUCIÓN GEOGRÁFICA DEL CRECIMIENTO NATURAL}

- En 2005 la tasa de crecimiento natural de la población era de $1.5 \%$ anual,

- países desarrollados: $0.5 \%$ anual

- países menos desarrollados: $2.0 \%$ anual

Clasificación:

a) Países con crecimiento natural bajo (menos del $1 \%$, incluso negativo)

b) Países con crecimiento medio (entre el 1 y el 1,5\% anual)

c) Países con crecimiento elevado (mayor del 1,5 \%) 


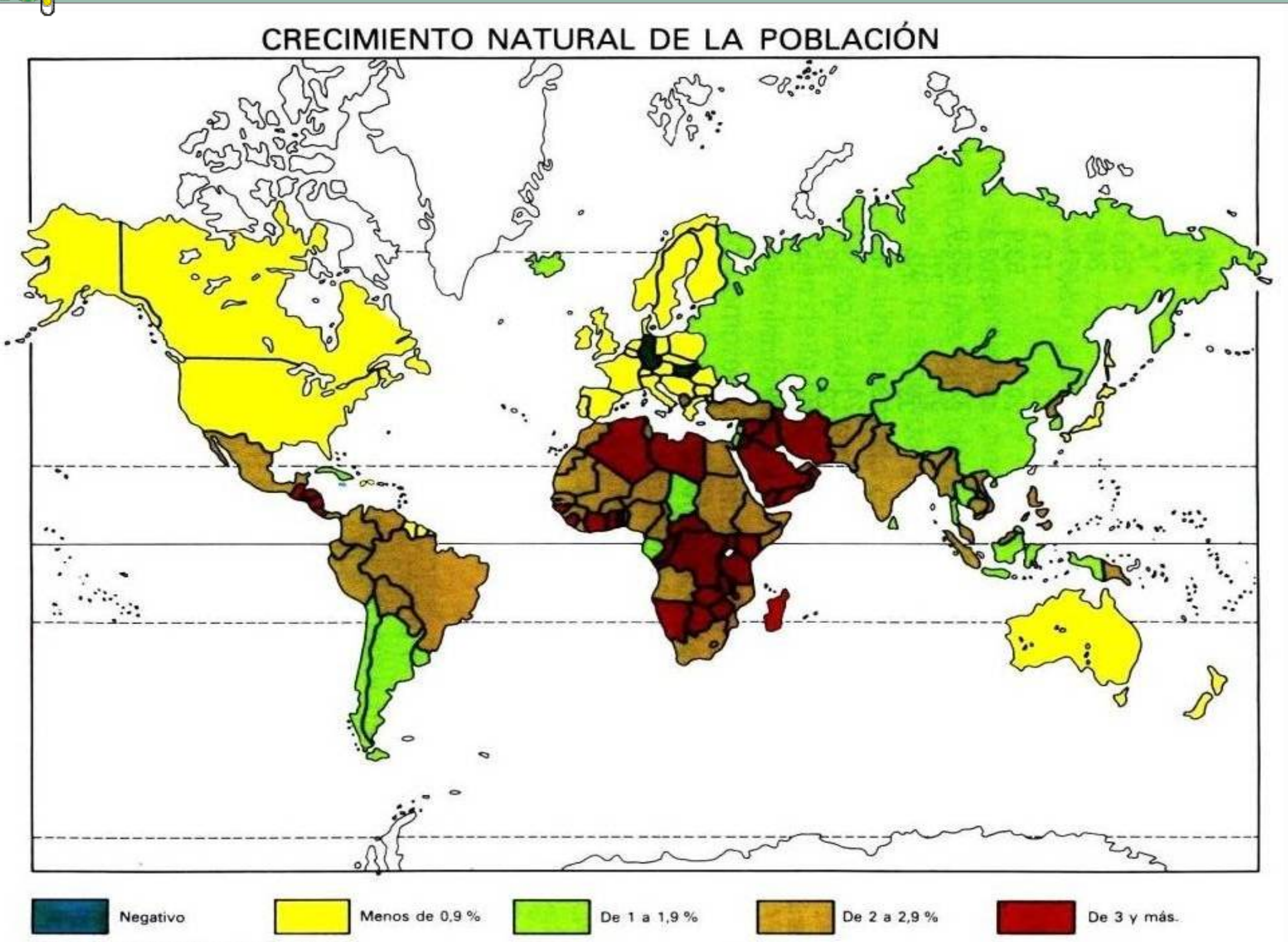

Fuente: Population Reference Bureau 1990 


\section{EVOLUCIÓN HISTÓRICA DEL CRECIMIENTO NATURAL}

- fuerte interrelación entre los procesos de desarrollo o modernización económica por un lado y la tendencia demográfica por otro

\section{Evolución histórica de la población}

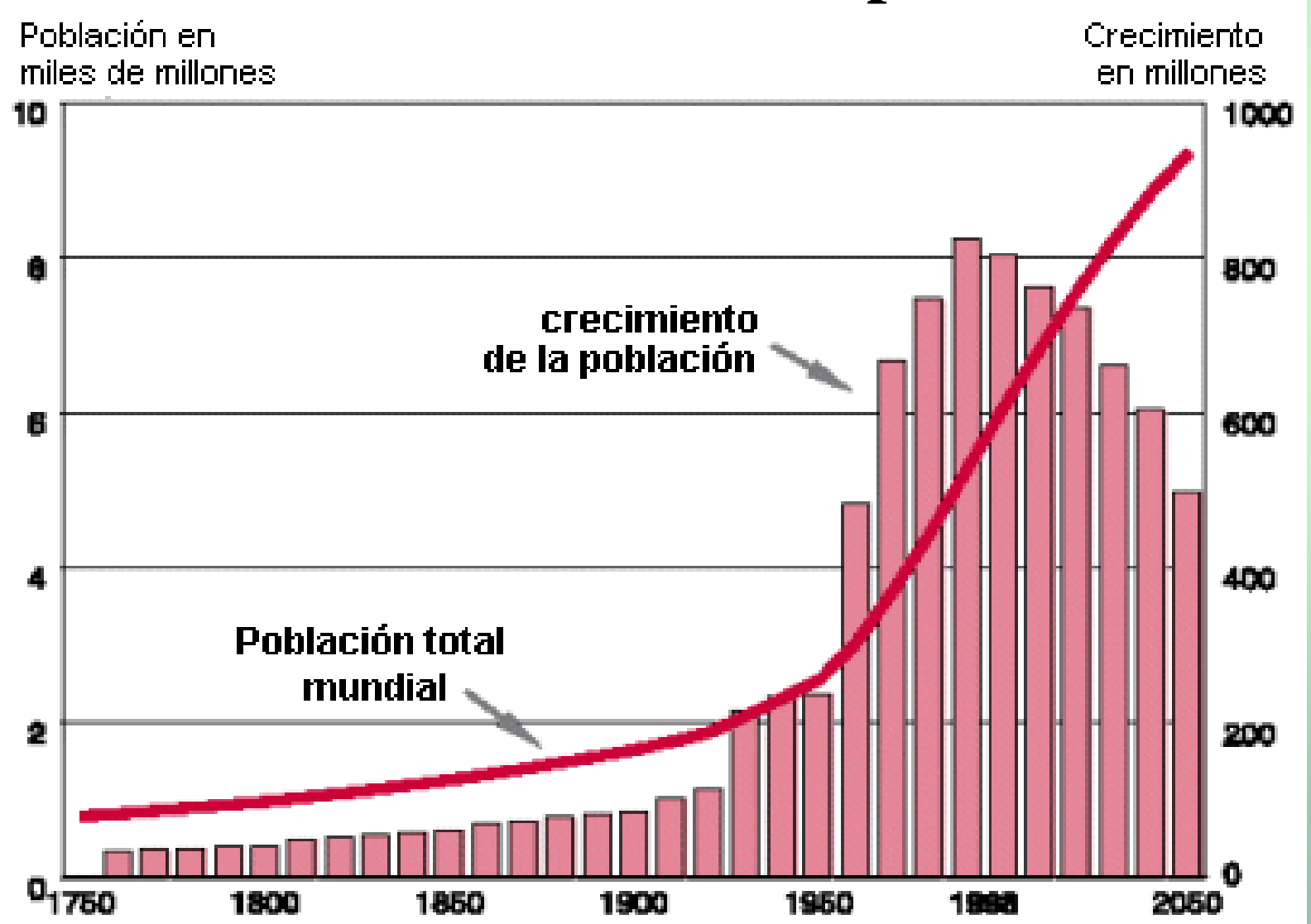

Publicado en formato digital: Dra. Ana María FOSCHIATTI. EI Movimiento Natural de la Población. Resúmenes. Revista Geográfica Digital. IGUNNE. Facultad de Humanidades. UNNE. Año 8. № 16. Julio - Diciembre 2011. Resistencia, Chaco. En: http://hum.unne.edu.ar/revistas/geoweb/default.htm 


\section{Teoría o modelo de la Transición demográfica}

Origen $\Longrightarrow$ explicar la relación entre los cambios demográficos y los socioeconómicos en Europa del S.XVIII

Describe $\Longrightarrow$ paso desde unas tasas muy altas de natalidad $y$ mortalidad de origen catastrófico, hasta unos niveles bajos y estabilizados de ambas variables

Proceso muy complejo y los países difieren tanto en el momento de inicio, en el ritmo de los cambios de la fecundidad y la mortalidad, en los cambios de otras variables relacionadas (estado nutricional, salud de la población, conductas matrimoniales y de planificación familiar) 


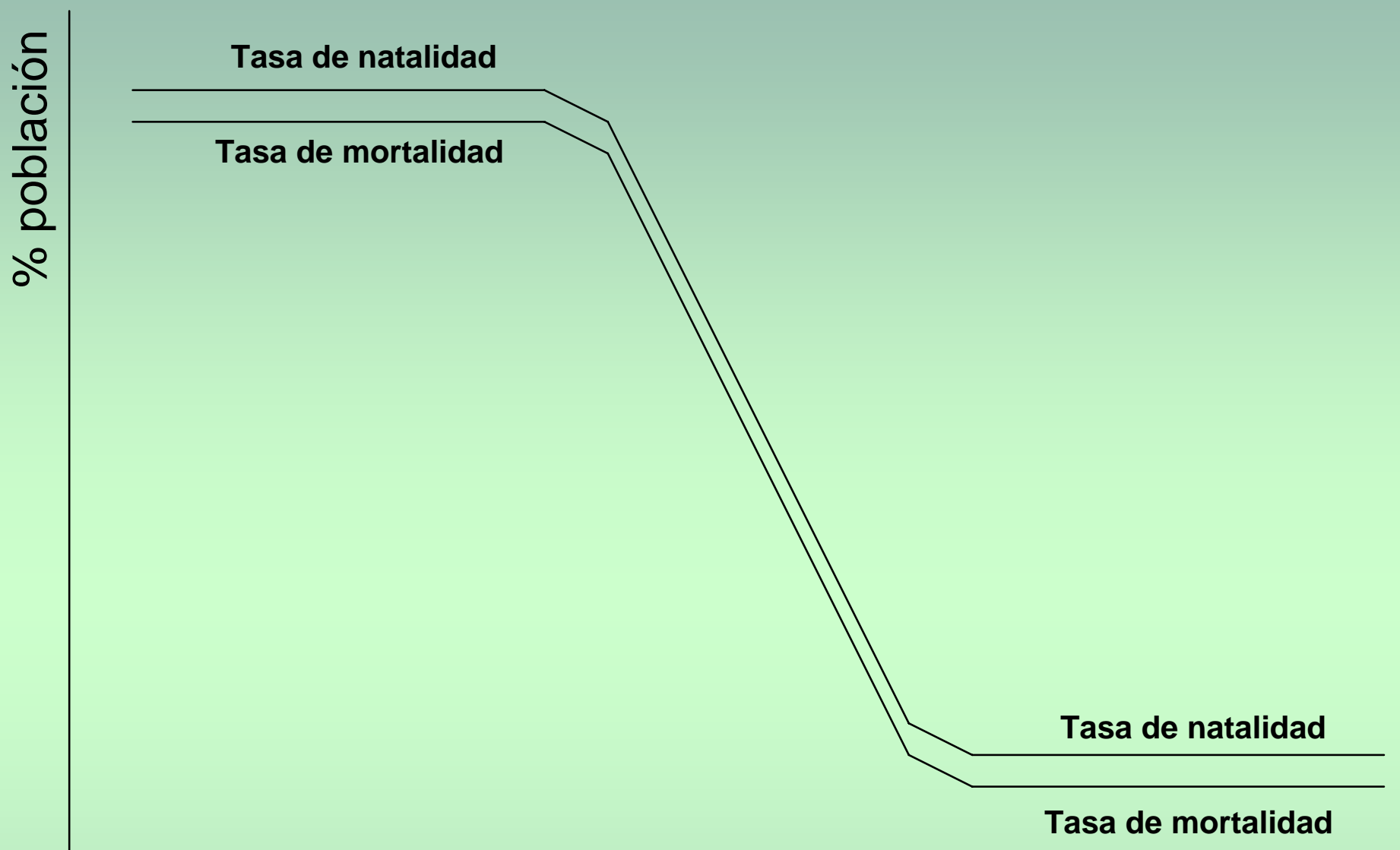

tiempo

En las sociedades primitivas, las tasas de natalidad y mortalidad son muy altas, y la población estable.

En las sociedades modernas, las tasas de natalidad y mortalidad son muy bajas, y la población estable.

Se llama "transición demográfica" al período de cambio de sociedad primitiva a moderna

Publicado en formato digital: Dra. Ana María FOSCHIATTI. EI Movimiento Natural de la Población. Resúmenes. Revista Geográfica Digital. IGUNNE. Facultad de Humanidades. UNNE. Año 8. № 16. Julio - Diciembre 2011. Resistencia, Chaco. En: http://hum.unne.edu.ar/revistas/geoweb/default.htm 


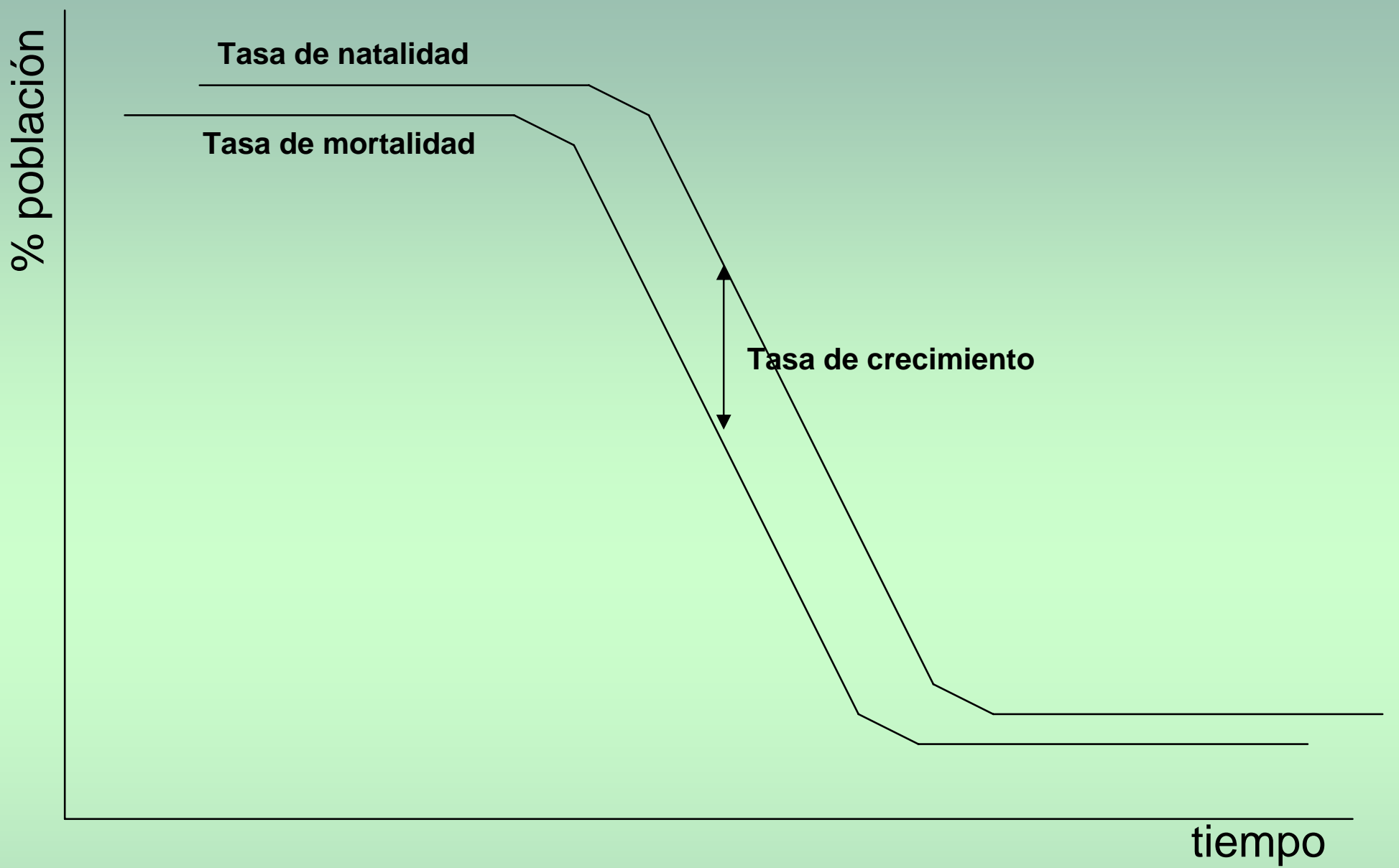

La tasa de mortalidad suele descender antes que la tasa de natalidad, por lo que durante el período de transición, la tasa de crecimiento es alta y la población aumenta.

\author{
coll@uma.es
}




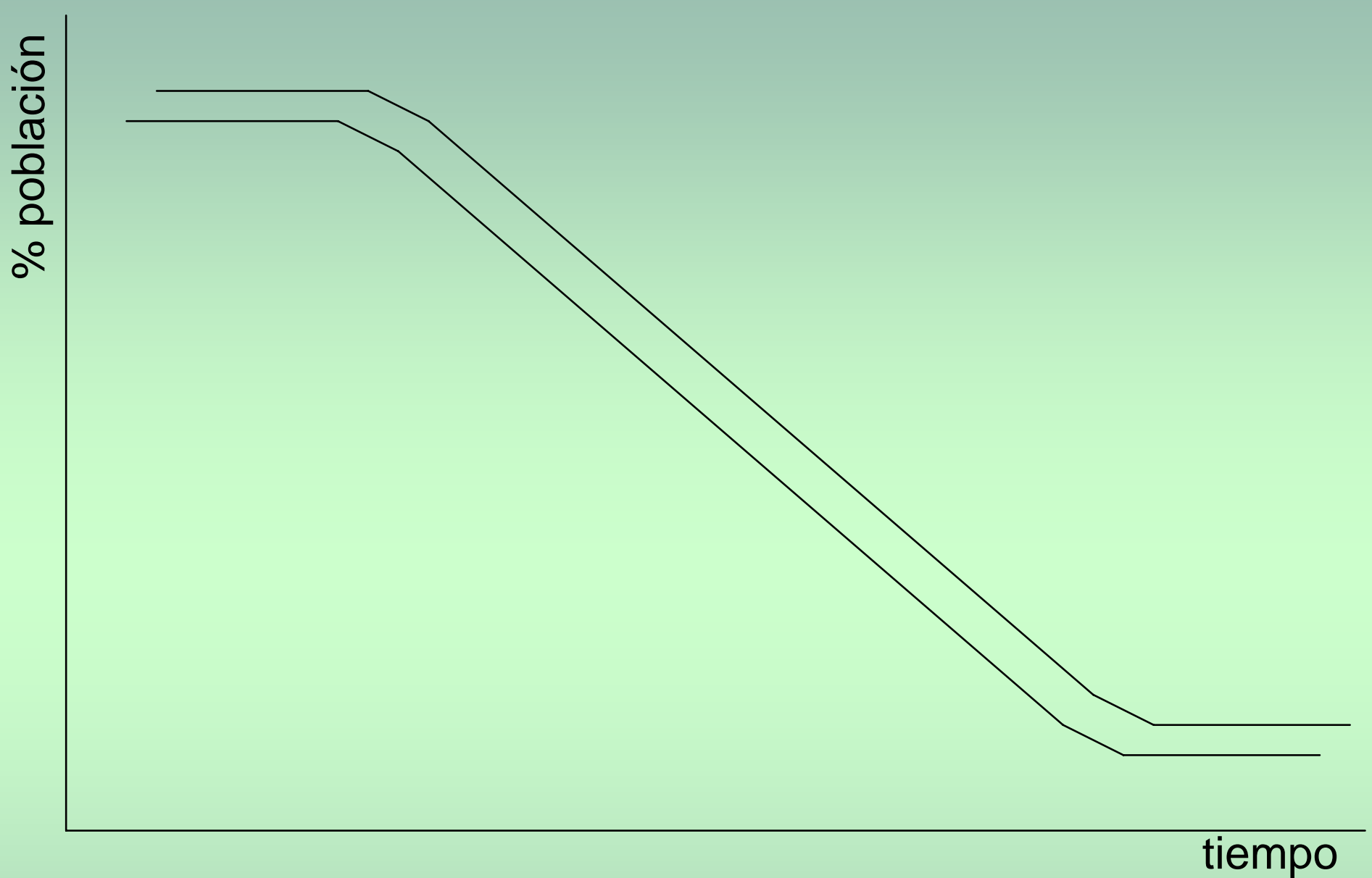

En los países europeos, la transición demográfica ha durado dos o tres siglos,

la diferencia entre las tasas de natalidad y mortalidad ha sido pequeña

y el crecimiento de la población ha sido relativamente lento 


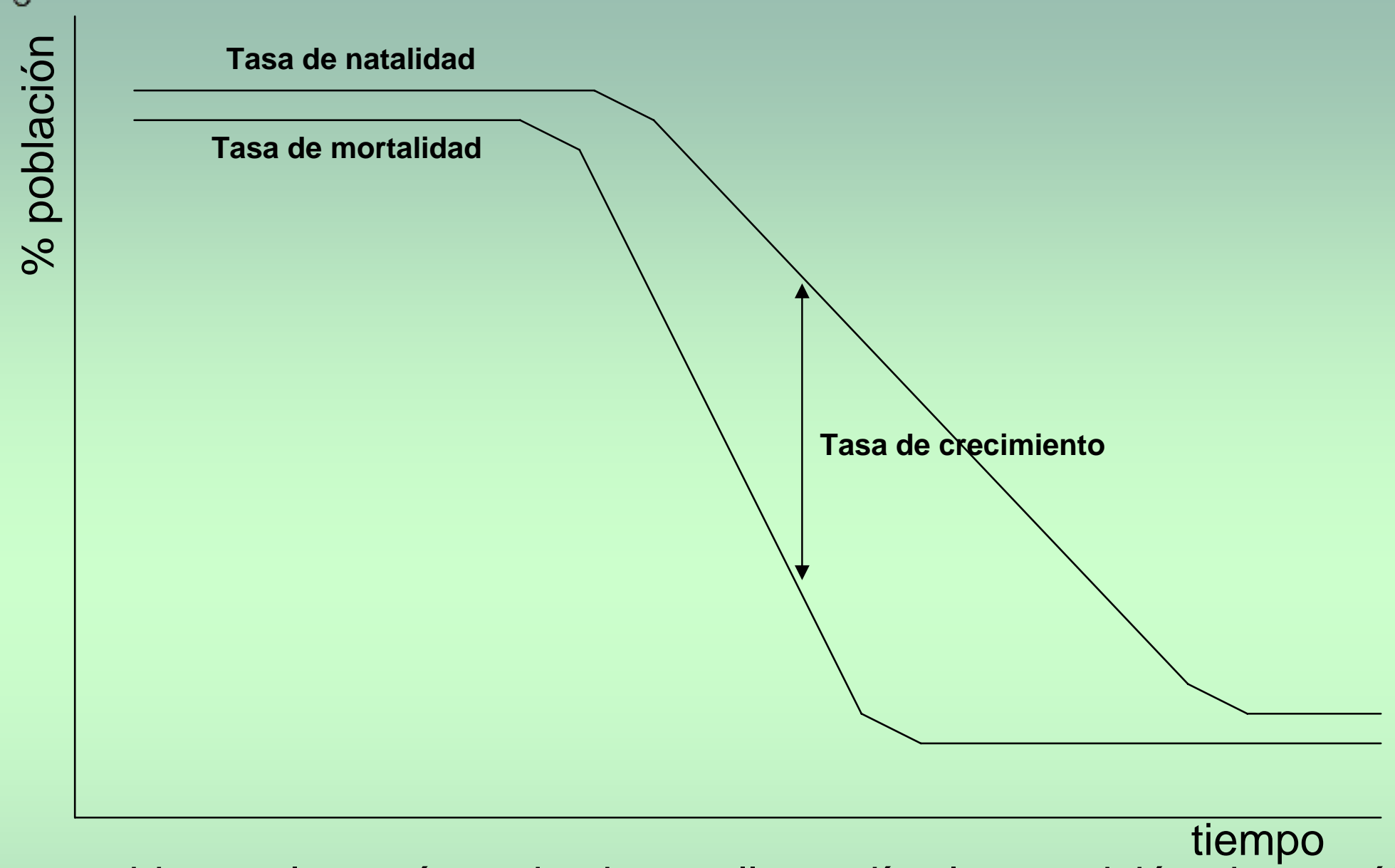

En cambio, en los países de desarrollo tardío, la transición demográfica se está produciendo de forma muy brusca.

- La tasa de mortalidad ha disminuido muy rápidamente.

- La tasa de natalidad está disminuyendo con lentitud.

- La tasa de crecimiento de la población es muy alta.

- La población crece de forma explosiva.

Publicado en formato digital: Dra. Ana María FOSCHIATTI. EI Movimiento Natural de la Población. Resúmenes. Revista Geográfica Digital. IGUNNE. Facultad de Humanidades. UNNE. Año 8. № 16. Julio - Diciembre 2011. Resistencia, Chaco. En: http://hum.unne.edu.ar/revistas/geoweb/default.htm 


\section{FASES}

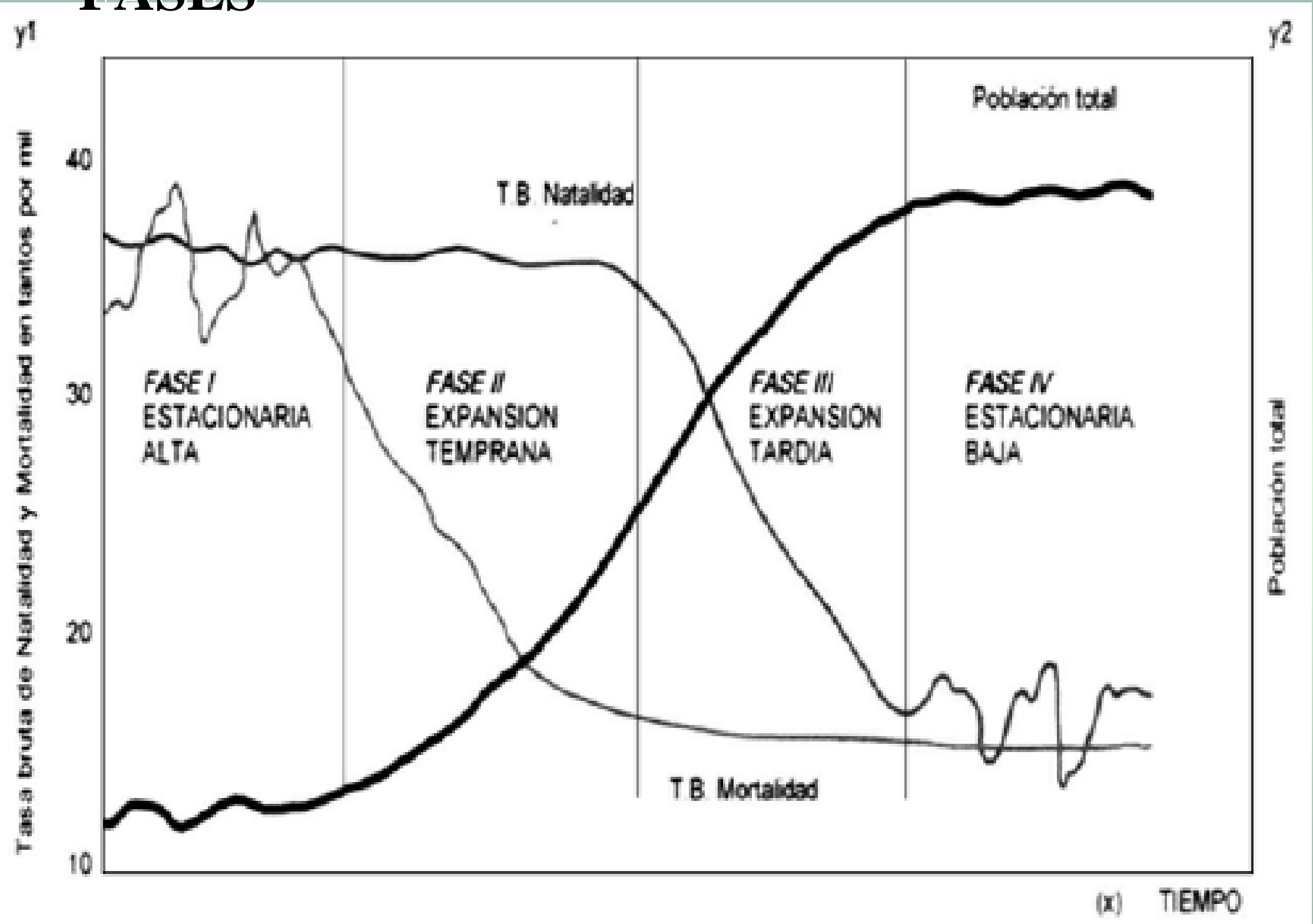

Publicado en formato digital: Dra. Ana María FOSCHIATTI. El Movimiento Natural de la Población. Resúmenes. Revista Geográfica Digital. IGUNNE. Facultad de Humanidades. UNNE. Año 8. № 16. Julio - Diciembre 2011. Resistencia, Chaco. En: http://hum.unne.edu.ar/revistas/geoweb/default.htm 


\section{Las etapas clásicas de la transición demográfica}

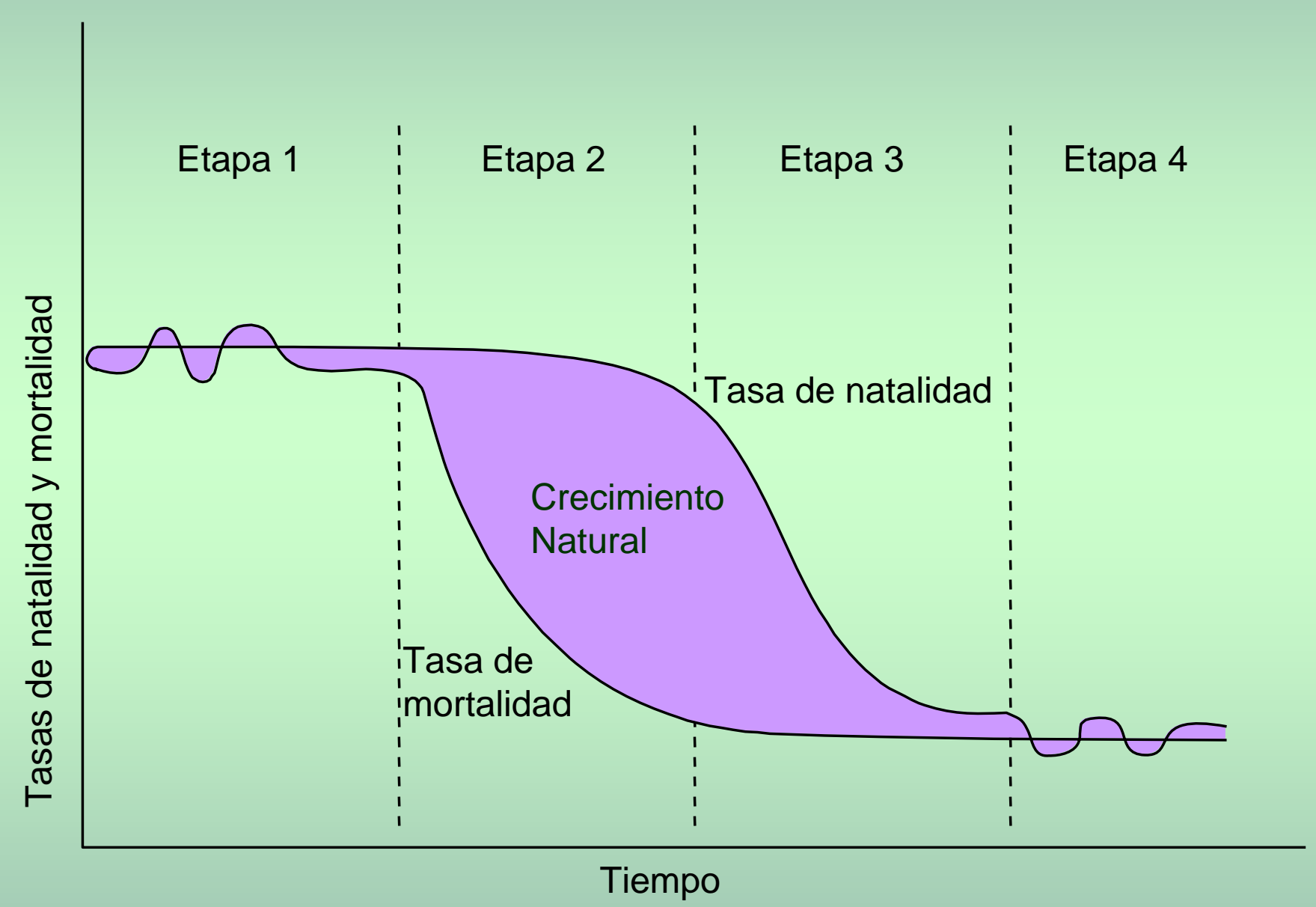




\section{Etapas de la transición demográfica}

\section{-Transición incipiente o}

pretransicional

-Transición inicial o moderada
Natalidad elevada (42 \% y más)

C. Natural $2 \%$ anual

Mortalidad elevada

Alta proporción de niños y jóvenes
Crecimiento

Bajo

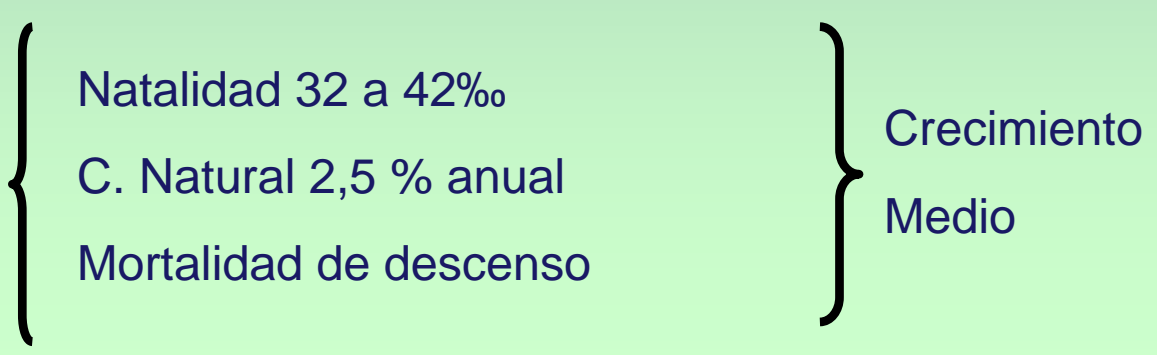

Natalidad en descenso (22 a 32\%)

C. Natural $3 \%$ anual

Crecimiento

Mortalidad de descenso

Estructura etaria Joven

Natalidad (menos de $22 \%$ )

Crecimiento Natural 1\%

Mortalidad Baja

Envejecimiento demográfico
Crecimiento

Débil 


\section{Modelo teórico de la transición demográfica}

1. Estacionaria Alta 2. Expansión temprana 3. Expansión moderna tardía 4. Estacionaria baja 5. En Declive

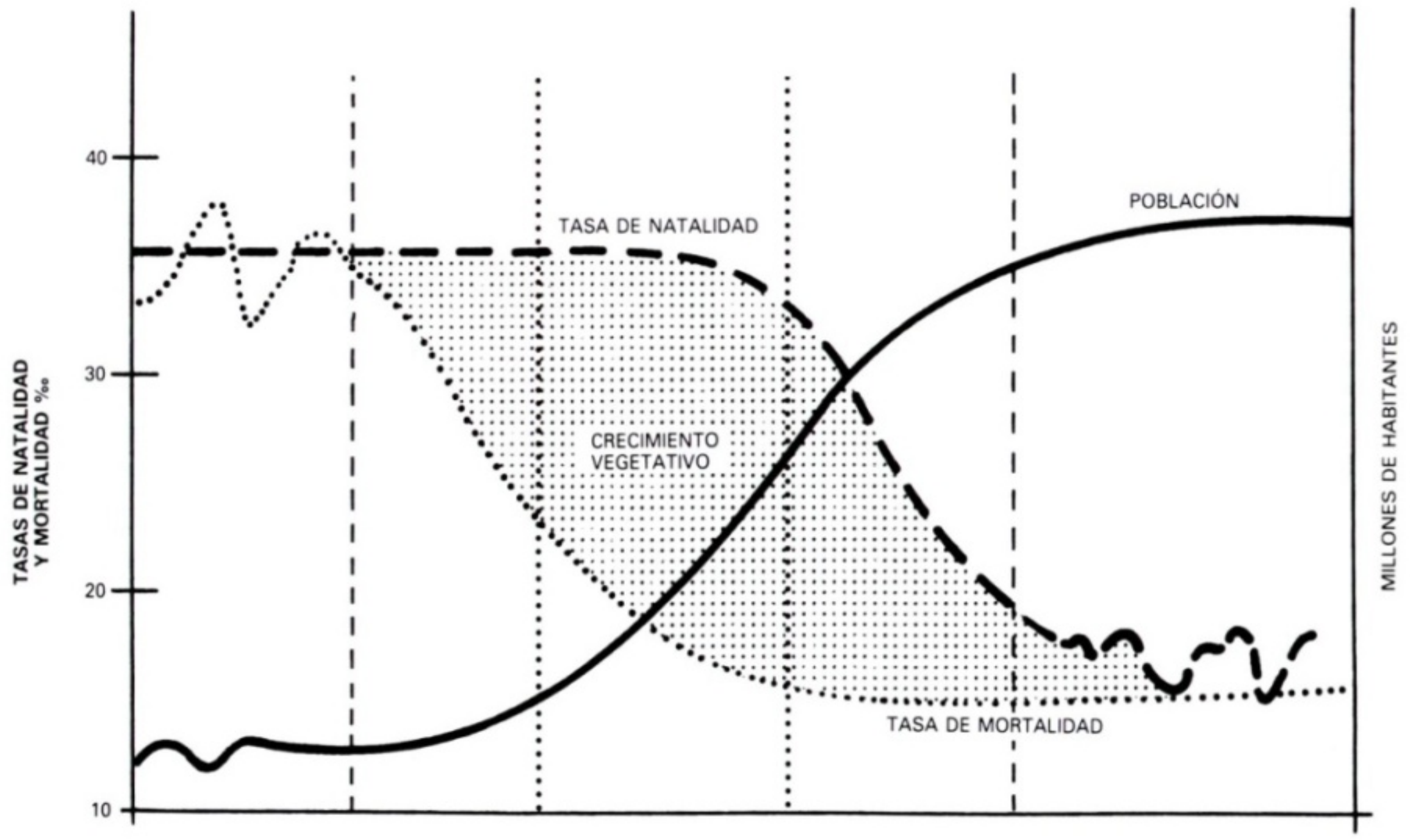

Publicado en formato digital: Dra. Ana María FOSCHIATTI. EI Movimiento Natural de la Población. Resúmenes. Revista Geográfica Digital. IGUNNE. Facultad de Humanidades. UNNE. Año 8. № 16. Julio - Diciembre 2011. Resistencia, Chaco. En: http://hum.unne.edu.ar/revistas/geoweb/default.htm 
Otros autores explican este modelo en tres fases principales que se inscriben en tres períodos históricos con diferentes comportamientos socio-demográficos:

a) Régimen demográfico antiguo: tasas de natalidad y mortalidad muy elevadas y la población apenas crece o lo hace lentamente

b) Transición demográfica: mortalidad baja y la natalidad sigue siendo muy elevada, se produce una Explosión demográfica

c) Régimen demográfico moderno: mortalidad y natalidad muy bajas y la población crece de forma muy lenta 


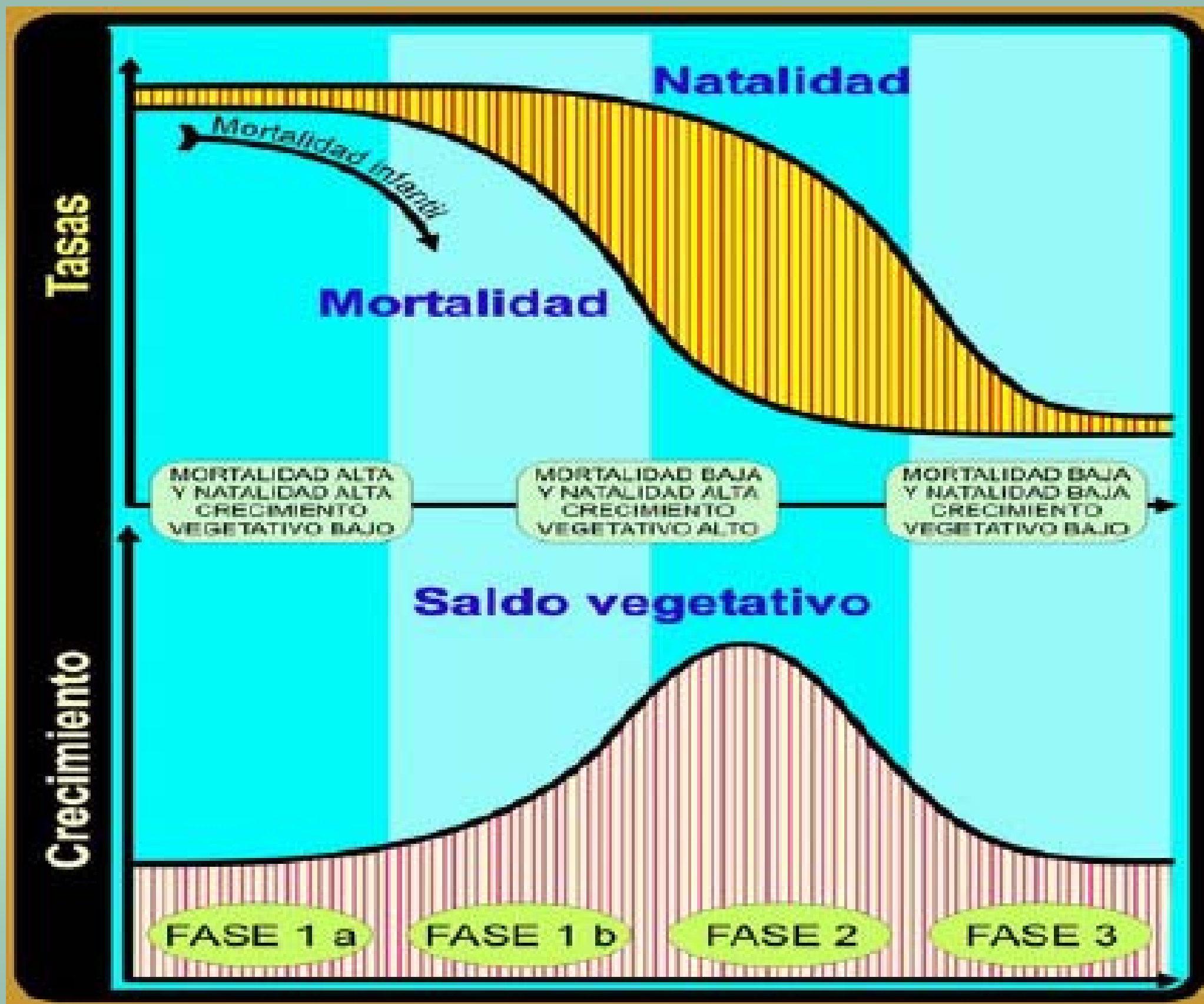

Publicado en formato digital: Dra. Ana María FOSCHIATTI. EI Movimiento Natural de la Población. Resúmenes. Revista Geográfica Digital. IGUNNE. Facultad de Humanidades. UNNE. Año 8. № 16. Julio - Diciembre 2011. Resistencia, Chaco. En: http://hum.unne.edu.ar/revistas/geoweb/default.htm 
Las características de los hechos que intervienen en la transición demográfica pueden sintetizarse de la siguiente manera:

\begin{tabular}{|c|c|c|c|}
\hline Régimen & NATALIDAD & MORTALIDAD & $\begin{array}{r}\text { CRECIMIENTO } \\
\text { NATURAL }\end{array}$ \\
\hline $\begin{array}{c}\text { Régimen } \\
\text { demográfico } \\
\text { antiguo } \\
\text { (Antes la Rev. } \\
\text { Industrial } \\
\text { hasta } \\
\text { principios } \\
\text { del siglo } \\
X X)\end{array}$ & $\begin{array}{l}\text { ALTA NATALIDAD: } \\
\text { - Valores elevados a principios } \\
\text { de siglo y descenso en el } \\
\text { último tercio del S.XIX. } \\
\text { - Economía y sociedades } \\
\text { rurales. Los hijos no } \\
\text { representaban demasiado gasto } \\
\text { en su crianza, colaboraban en } \\
\text { las tareas agrícolas y } \\
\text { aseguraban el porvenir y } \\
\text { la vejez de los padres al no } \\
\text { haber seguros de accidentes o } \\
\text { jubilación. } \\
\text { - No existían controles } \\
\text { eficaces para el control de la } \\
\text { natalidad, más que el retraso en } \\
\text { la edad del matrimonio. }\end{array}$ & $\begin{array}{l}\text { ALTA MORTALIDAD: } \\
\text { - Mortalidad alta y oscilante. La } \\
\text { escasa productividad agrícola } \\
\text { provocaba ciertos desequilibrios } \\
\text { alimenticios. La falta de proteínas } \\
\text { ocasionaba problemas de nutrición y } \\
\text { debilidad en la población que la } \\
\text { exponía a las enfermedades con } \\
\text { mayor facilidad (el pan era el } \\
\text { alimento básico). } \\
\text { - Alta incidencia de enfermedades } \\
\text { infecciosas y parasitarias } \\
\text {-(tuberculosis, cólera, gripe, diarreas, } \\
\text { etc.) por la falta de higiene pública y } \\
\text { privada, el desconocimiento de las } \\
\text { vías de transmisión y el atraso de la } \\
\text { medicina, } \\
\text { - Reiterada ocurrencia de } \\
\text { mortalidad por epidemias, guerras y } \\
\text { malas cosechas. } \\
\text { - Alta mortalidad infantil, por } \\
\text { anomalías congénitas y problemas en } \\
\text { el parto, como así por enfermedades } \\
\text { infecciosas y desnutrición. }\end{array}$ & $\begin{array}{l}\text { CRECIMIENTO } \\
\text { NATURAL } \\
\text { BAJO: } \\
\text { Las constantes } \\
\text { crisis de } \\
\text { sobremortalidad } \\
\text { afectaban } \\
\text { seriamente a las } \\
\text { oscilaciones del } \\
\text { crecimiento } \\
\text { vegetativo que lo } \\
\text { mantenían en } \\
\text { valores muy } \\
\text { bajos. }\end{array}$ \\
\hline
\end{tabular}




\section{Transición} demográfica (1900-1970)

Paso del régimen

Demográfico antiguo al actual.
DESCENSO DE FORMA SUAVE

Y DISCONTINUA DE LA NATALIDAD:

- A principios de siglos produce prosperidad económica

y recuperación de la natalidad.

- Entre 1930 y 50: se reanuda el descenso por la crisis económica, la inestabilidad política, la situación de posguerra (exilio y dificultades económicas). Se instituye una política pronatalista y prohíben los anticonceptivos.

- Entre 1950 y 65 se recupera la natalidad, se produce el baby-boom postbélico (retrasado en algunos países)

-En los últimos años el desarrollo económico, la culminación de las migraciones campo-ciudad y los problemas de vivienda provocaron una nueva reducción.
DESCENSO NOTABLE Y CONSTANTE DE LA MORTALIDAD

- $\quad$ Avances médicos y sanitarios:

Descubrimiento de las vacunas y antibióticos que permitieron la desaparición de epidemias y la reducción de las enfermedades infecciosas.

- $\quad$ Aumento del nivel de vida: debido a la mejora de la dieta alimenticia.

- El incremento del nivel educativo y cultural aumentó la prevención de enfermedades $y$ el abandono de hábitos nocivos para la salud.

- Los progresos en la pediatría, el aumento de los nacimientos con asistencia médica, el mejoramiento de la sanidad pública y de la higiene pública y privada disminuyeron la mortalidad infantil sobre todo la causada por infecciones, la desnutrición y el cuidado materno (disminución de la mortalidad neonatal $y$ femenina en parto $y$ posparto)
CRECIMIENTO

NATURAL

ALTO:

- Especialmente entre 1910 y 1960

periodo en el que la mortalidad descendió fuertemente, mientras que la natalidad pasó por dos máximos separados por las Guerras.

- Desde 1960, el crecimiento se hace más lento porque la mortalidad logró cifras bajas, aunque más lentamente, $y$ la natalidad disminuyó de manera rápida. 
- Bajas tasas de natalidad. Se mantiene un comportamiento malthusiano, con algunos síntomas de recuperación debido a la inmigración.

- Las crisis económicas aumentaron el paro y ello retrasó la edad al matrimonio. La escasez de trabajos de tiempo parcial y guarderías accesibles agravaron esta situación.

- Se produjo un cambio de mentalidad, se extendió el uso de anticonceptivos y se despenalizó el aborto en algunos supuestos. La incorporación de la mujer al trabajo, que pospone la edad de maternidad y el surgimiento de formas familiares distintas al matrimonio y con menos hijos también se encuentran dentro de este cambio.

- El aumento cultural y de nivel de vida cambió la valoración de los hijos. Hoy no son un reaseguro sino que se pretende dar unas mejores condiciones de vida (se prefiere así una familia menos numerosa), ya que requieren básicamente gastos $y$ dedicación.
Baja mortalidad. La mortalidad se mantiene en cifras bajas ( 8,7 en 2004). Desde 1981 experimenta cierto ascenso debido a la llegada de una amplia población vieja a su techo biológico. Se produce un aumento de la esperanza de vida (en 2004 las mujeres rondaban los 83 años y los hombres los 75).

- Disminuye la importancia de las enfermedades infecciosas y aumentan las llamadas CCC (enfermedades cardiovasculares, cáncer y accidentes de carretera). Debido al envejecimiento de la población aumentan los casos de Alzheimer o demencia senil.

- La mortalidad infantil es baja,, principalmente neonatal. En 2004 era de 3,9\%. Todavía tiene margen para reducirse gracias a avances médicos.

- La mortalidad presenta diferencias entre los sexos y las profesiones. La esperanza de vida en mujeres es mayor, debido a las diferencias biológicas y al estilo de vida que tradicionalmente han tenido los hombres: trabajos con mayor índice de riesgo o hábitos nocivos en exceso: como alcohol o tabaco
-El crecimiento natural es bajo como

consecuencia de las tasas de natalidad y mortalidad reducidas. El 0,09\%。 en 2004. -El estancamiento de la natalidad, el envejecimiento de la población y el aumento de la mortalidad debido a la llegada al techo biológico de la población con más de 65 años, continuarán con las tendencias actuales. 


\section{EL COMPORTAMIENTO DE LOS MODELOS DEMOGRÁFICOS}

La comparación de los índices de natalidad y mortalidad arroja resultados muy diferentes. En los países desarrollados se registran los siguientes regímenes:

- Régimen antiguo: elevadas tasas de natalidad y mortalidad con débil y discontinuo crecimiento de la población. Cronológicamente abarca hasta el siglo XVIII (fase I).

- Régimen de transición: la tasa de natalidad continúa siendo muy alta, pero desciende la de mortalidad, y se produce, en consecuencia, una explosión demográfica. Primero se reduce la mortalidad catastrófica por epidemias y después desciende la mortalidad ordinaria gracias a las mejores condiciones higiénicas y a los avances médicos. Coincide con el desarrollo de la Revolución Industrial (fase II).

- Régimen moderno: las tasas de natalidad y de mortalidad son muy bajas, por lo que el crecimiento de la población es débil o nulo. La reducción de la fecundidad se asocia a mejoras económicas. Se produce durante gran parte del siglo XX (fases III y IV).

- Régimen regresivo: la tasa de natalidad sigue siendo baja, pero aumenta la de mortalidad debido al elevado número de población envejecida. Esta circunstancia provoca un crecimiento natural negativo que conduce a una involución demográfica (fase V). 


\section{Ventajas e inconvenientes de los distintos regímenes demográficos.}

\begin{tabular}{|c|c|c|}
\hline $\begin{array}{l}\text { Tipo de } \\
\text { Régimen }\end{array}$ & VENTAJAS & INCONVENIENTES \\
\hline $\begin{array}{c}\text { Régimen } \\
\text { demográfico } \\
\text { joven }\end{array}$ & $\begin{array}{l}\text { Existe poca dependencia de los } \\
\text { Grupos de edad viejos en la } \\
\text { población activa. } \\
\text { Hay elevada reserva de población } \\
\text { activa para el futuro; } \\
\text { La mano de obra es barata. } \\
\text { Se rejuvenecen los cuadros } \\
\text { dirigentes. } \\
\text { Aumenta la capacidad de iniciativa. }\end{array}$ & $\begin{array}{l}\text { La población aumenta más rápidamente que } \\
\text { los recursos. } \\
\text { El rápido incremento de la población joven } \\
\text { provoca una desproporción de los gastos } \\
\text { de escolarización y de viviendas. } \\
\text { La rápida escasez de puestos de trabajo } \\
\text { puede provocar un aumento de la } \\
\text { emigración. } \\
\text { No hay incentivo para el ahorro y la } \\
\text { inversión. }\end{array}$ \\
\hline $\begin{array}{c}\text { Régimen } \\
\text { demográfico } \\
\text { viejo }\end{array}$ & $\begin{array}{l}\text { Son casi inexistentes los problemas } \\
\text { de relación entre población y } \\
\text { recursos. } \\
\text { Escasa dependencia económica de } \\
\text { los grupos de edades jóvenes sobre } \\
\text { los grupos que trabajan. } \\
\text { Abunda el empleo. } \\
\text { Se produce escasa emigración. } \\
\text { Se propende el ahorro e la } \\
\text { inversión. }\end{array}$ & $\begin{array}{l}\text { El aumento de ancianos incrementa los } \\
\text { gastos de asistencia social. } \\
\text { Disminuye rápida y progresivamente la } \\
\text { población activa. } \\
\text { Se encarece la mano de obra. } \\
\text { Envejecen los cuadros dirigentes. } \\
\text { Disminuye la capacidad de iniciativa y de } \\
\text { cambio en la sociedad. }\end{array}$ \\
\hline
\end{tabular}




\section{Transición demográfica en el mundo}

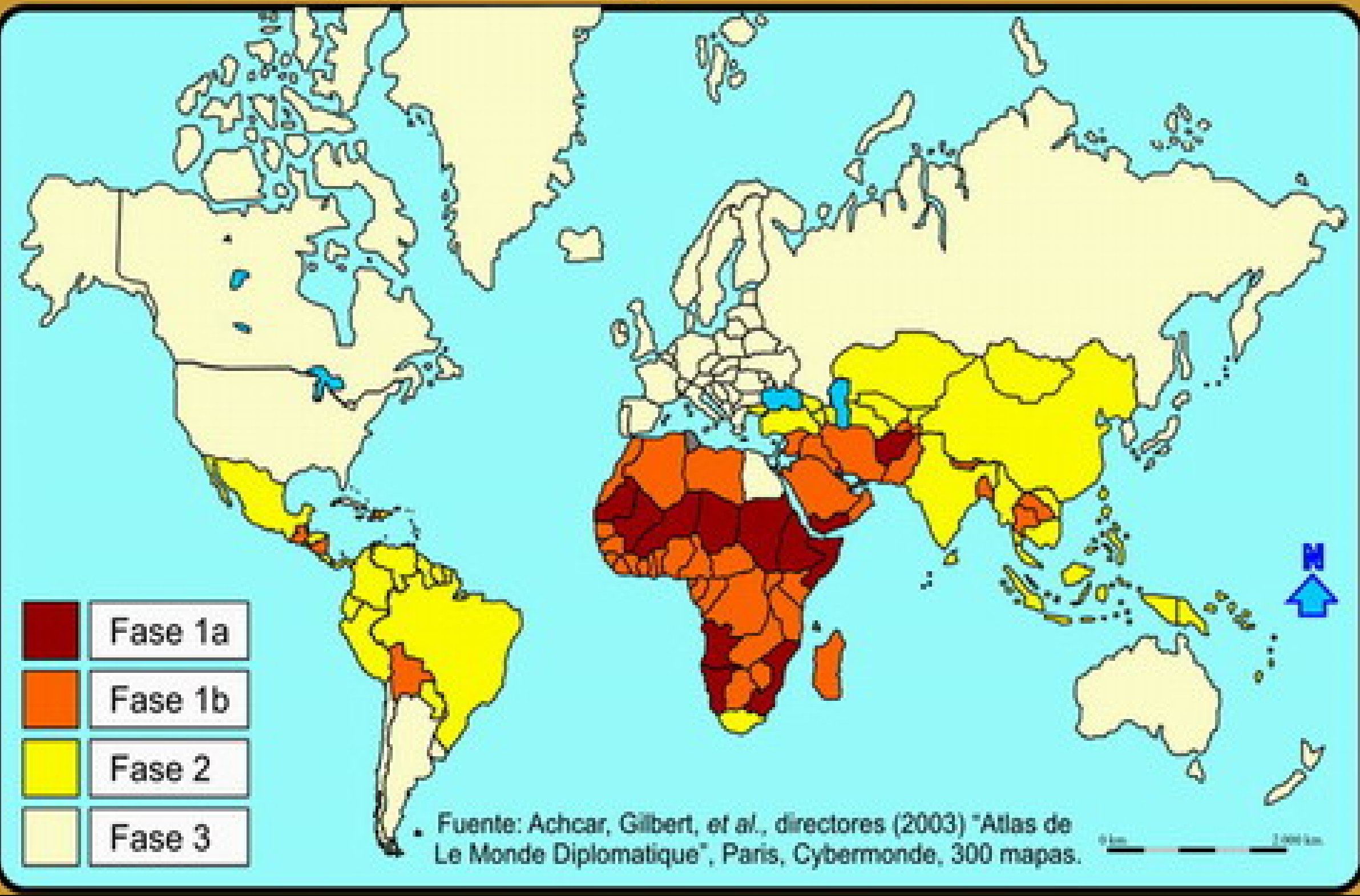

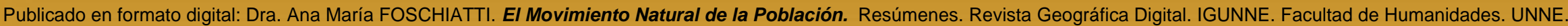
Año 8. No 16. Julio - Diciembre 2011. Resistencia, Chaco. En: http://hum.unne.edu.ar/revistas/geoweb/default.htm 


\section{FIECHOS DESTACADOS}

- Explosión demográfica: tiene lugar cuando en un país se produce un crecimiento espectacular de población a causa de una alta tasa de natalidad y un descenso en picada de la mortalidad. En algunos casos se añade la llegada masiva de emigrantes.

- Involución demográfica: fenómeno demográfico por el que una población en continuo crecimiento cambia de signo y presenta una disminución del número de nacimientos ante un aumento de la tasa de mortalidad. 


\section{Los procesos demográficos de larga duración}

Procesos de cambio
-Transición demográfica
-Segunda transición $\longrightarrow$ descenso de la natalidad y mortalidad




\section{La transición urbana y de la movilidad}

La transición urbana se explica por el aumento sostenido de la proporción de población urbana y el estancamiento demográfico de las áreas rurales, que es acompañado por un cambio de las conductas de movilidad

Independientemente de la etapa de transición urbana que se trate, la localización de la población conduce a la existencia de dos riesgos fundamentales: la dispersión de la población rural con la proliferación de ciudades de pequeño tamaño y la instalación de las personas en áreas precarias o expuestas a problemas ambientales 


\section{La transición urbana y de la movilidad}

Implica $\left\{\begin{array}{l}\cdot \text { Aumento sostenido de la proporción de Población Urbana } \\ \bullet \text { Cambios de conductas de movilidad }\end{array}\right.$

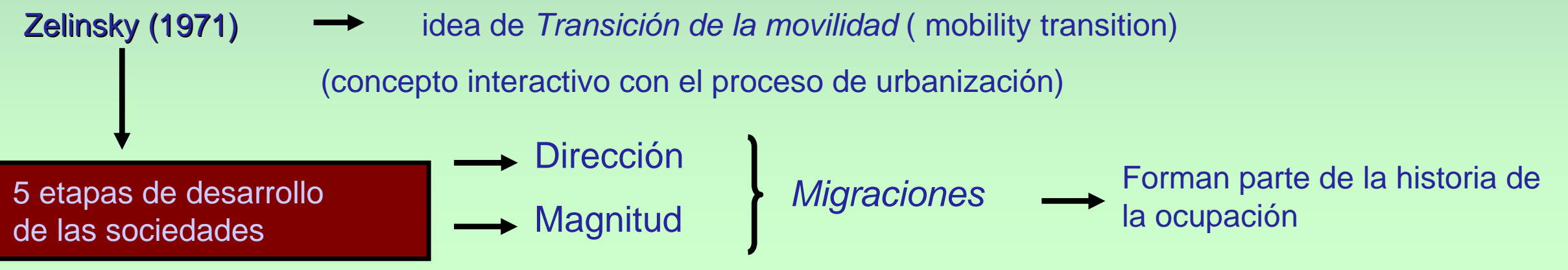

1. Sociedad Tradicionales premodernas $\longrightarrow$ Escasa migración genuina de acuerdo c/prácticas
2. Sociedad en estado de uso de la tierra, las reglas comerciales, los rituales religiosos.
3. Sociedad en estado avanzado de transición


4. Sociedades avanzadas

- Decrece la importancia de la migración campo - ciudad.

- Incrementan los intercambios interurbanos y dentro de las ciudades

- Migración de países pobres a ricos (trabajadores poco calificados)

- Decae el movimiento de frontera

- Movilidad y circulación internacional de trabajadores calificados.

- Reducción de desplazamientos a áreas de colonización.

- Movilidad global con fines turísticos

5. Sociedades futuras superavanzadas

- Desaceleración de la migración residencial.

- Aumento de la movilidad intraurbana.

- Control de la migración internacional.

- Redistribución dentro de las ciudades.

•Intensificación de la "rururbanización" 


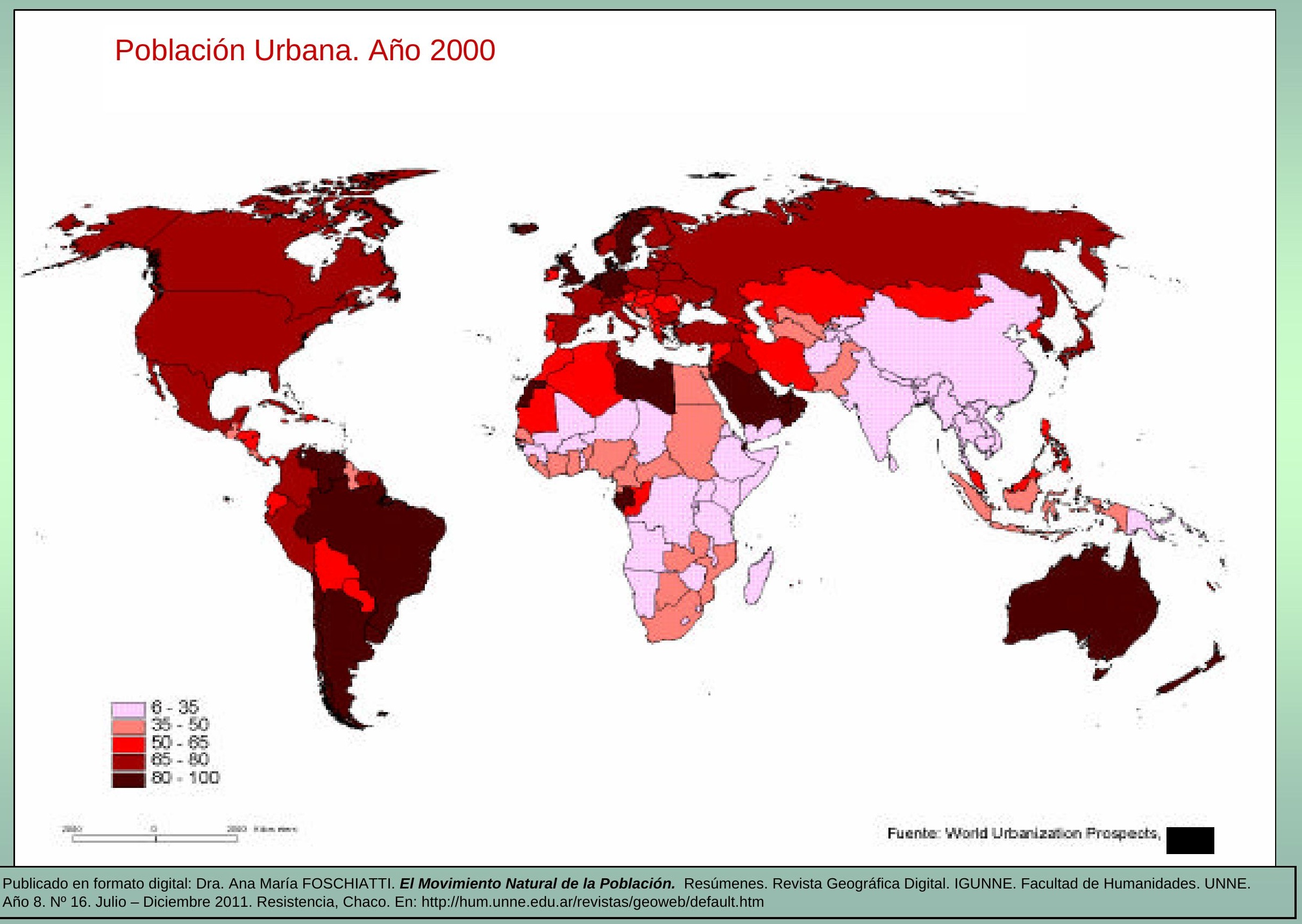



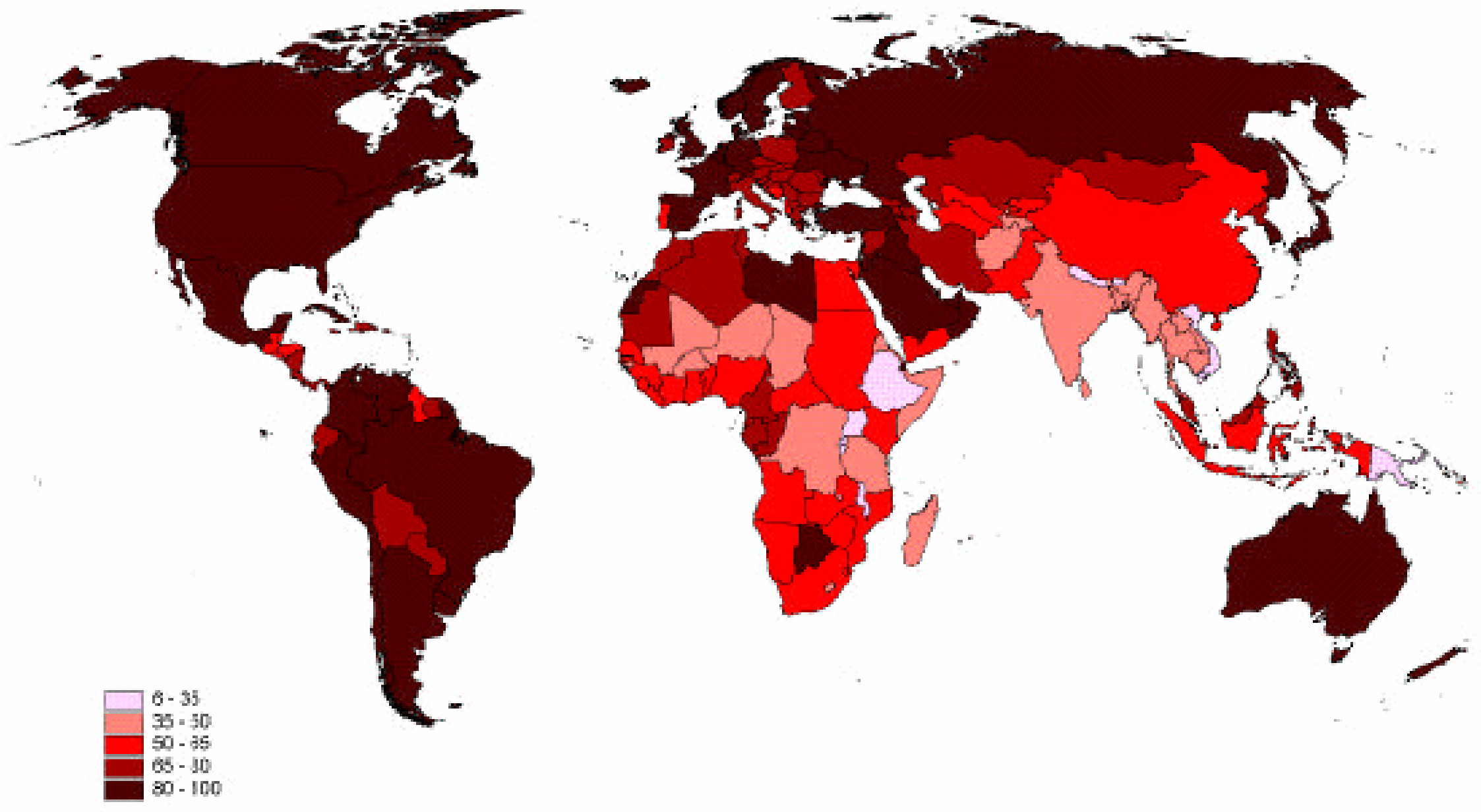

mes

Fuente: World Uibanization Prosoects,

Publicado en formato digital: Dra. Ana María FOSCHIATTI. El Movimiento Natural de la Población. Resúmenes. Revista Geográfica Digital. IGUNNE. Facultad de Humanidades. UNNE. Año 8. № 16. Julio - Diciembre 2011. Resistencia, Chaco. En: http://hum.unne.edu.ar/revistas/geoweb/default.htm 


\section{La sequnda transición demográfica}

- la segunda transición demográfica implica modificaciones en los patrones de reproducción de las familias y de la nupcialidad (aumento de la edad al casarse, uniones de hecho, procreación extramatrimonial, disoluciones matrimoniales), que condujo a índices de fecundidad por debajo de los niveles de reemplazo (2,1 Hijos por mujer) y al crecimiento negativo de algunos países 


\section{La segunda transición}

Modificaciones

Patrones de reproducción (debajo del nivel de reemplazo)

Patrones de nupcialidad (retraso del matrimonio y del primer hijo uniones informales y divorcios)

riesgos<smiles>[AlH2]</smiles>

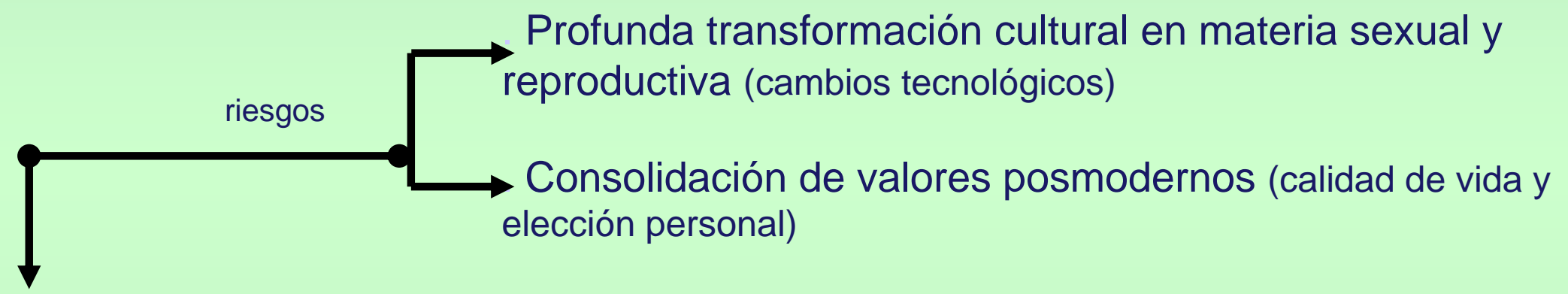

- Incremento de la soltería

- Aumento de los Nacimientos extramatrimoniales

- Postergación de las uniones

- Postergación de la maternidad-paternidad hasta alcanzar mejor nivel educativo y económico.

- Aumento de las Uniones consensuales

- Abandono de la mujer ( aumento de las mujeres jefes de hogar)

- Inestabilidad familiar y diversificación de las modalidades de estructuración familiar

- Mayor frecuencia de las rupturas matrimoniales 


\section{La transición Epidemiolóqica}

- Es el cambio de las características de la morbilidad, las causas de muertes y la distribución por edad de las defunciones.

El proceso consiste en la disminución proporcional de las muertes ocasionadas por enfermedades perinatales y las transmisibles (infecciosas, parasitarias y respiratorias) dando paso a las crónicas y degenerativas (tumores, circulatorias) y las provocadas por causas externas (violencia, accidentes, traumatismos ) 


\section{Transición epidemiológica}

Transición
Demográfica

Transición
de la mortalidad

\section{Transición \\ epidemiológica}

\section{Cambio operado a través del tiempo en las}

características de la morbilidad, las causas de

muerte y la distribución por edades de las

defunciones.

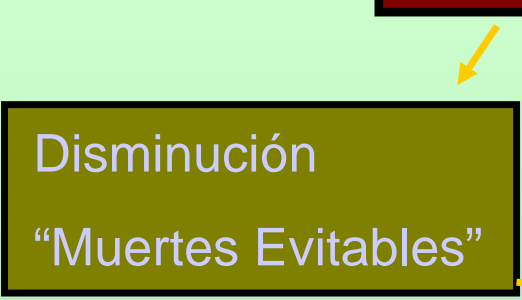

$\downarrow$

Niños y jóvenes

\section{Afectal}

Estructura etaria de las muertes

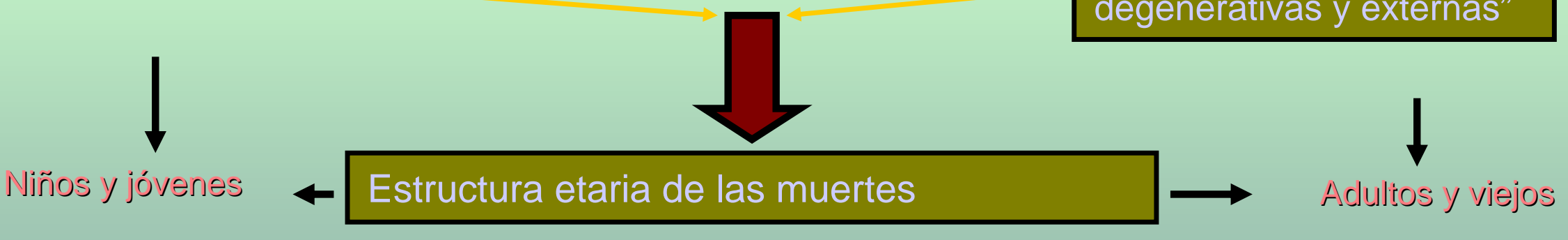

Aparición

"Causas crónicas, degenerativas y externas"

Publicado en formato digital: Dra. Ana María FOSCHIATTI. EI Movimiento Natural de la Población. Resúmenes. Revista Geográfica Digital. IGUNNE. Facultad de Humanidades. UNNE. Año 8. № 16. Julio - Diciembre 2011. Resistencia, Chaco. En: http://hum.unne.edu.ar/revistas/geoweb/default.htm 
Teoría: Transición epidemiológica

(Abdel Omram - 1971)

En relación con la transición demográfica y con el nivel socioeconómico

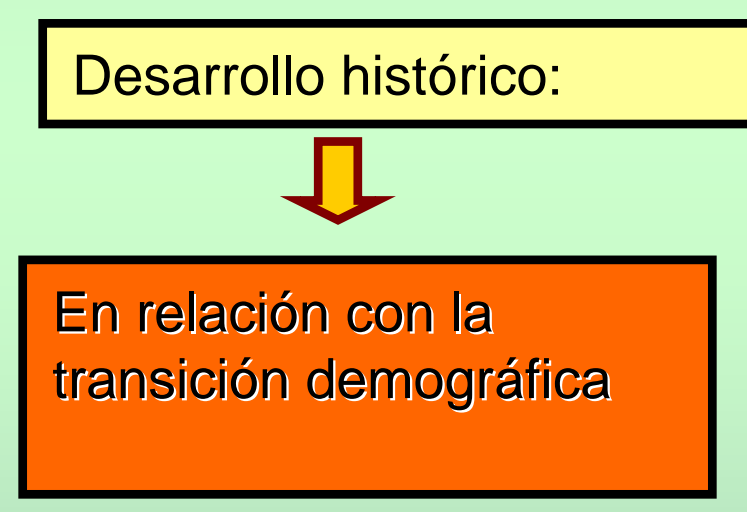

\section{Edad de la peste y el hambre.}

- Mortalidad alta y fluctuante

- e o baja

- Crecimiento escaso de la población

2. Edad de las pandemias retraídas.

- Mortalidad media

- $\mathrm{e}_{\mathrm{o}}$ se incrementa

- Crecimiento demográfico sostenido

3. Edad de las enfermedadles degenerativas y provocadas por el hombre.

- Mortalidad baja y estable

- $\mathrm{e}_{\mathrm{o}}$ en aumento

- Fecundidad: hecho decisivo para controlar el crecimiento. 

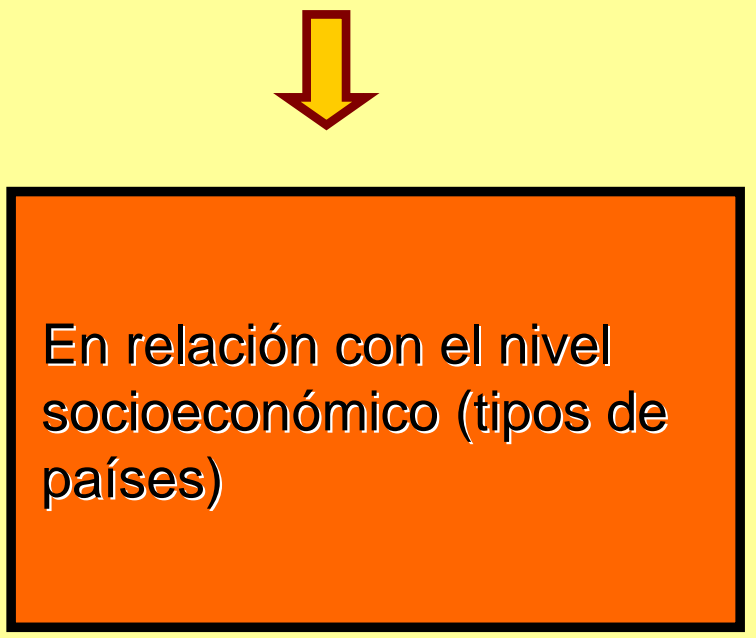

1. Primera fase: Países pobres. Enfermedades infecciosas, y nutricionales.

2. Segunda fase: Países en Vías de desarrollo. Mejor nivel socioeconómico. Mejores medidas de higiene.

3. Tercera fase: Países en transición. Cambios en la alimentación y estilos de vida.
Mort. Inf. Alta.

e o corta

Factores de riesgo cardiovascular. Prevalencia de Enfermedades Infecciosas.

Riesgo cardiovascular. Vida sedentaria, estrés, obesidad

Disminuyen los riesgos cardiovasculares por mejora en la concientización en los estratos población más elevados. 
G Revista Geográfica Digital. IGUNNE. Facultad de Humanidades. UNNE. Año 8. № 16. Julio - Diciembre 2011. ISSN 1668-5180 Resistencia, Chaco Fases de la transición epidemiológica

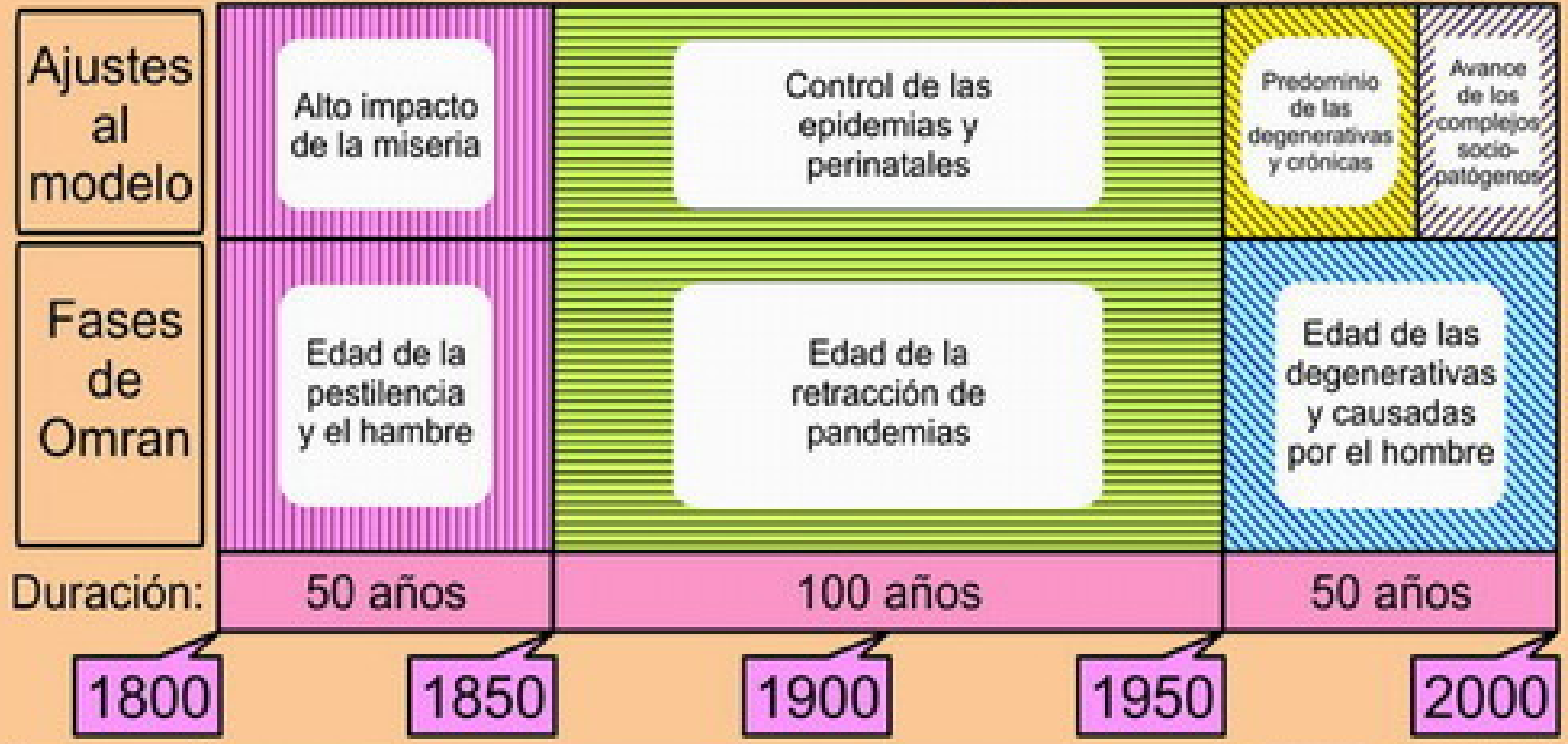

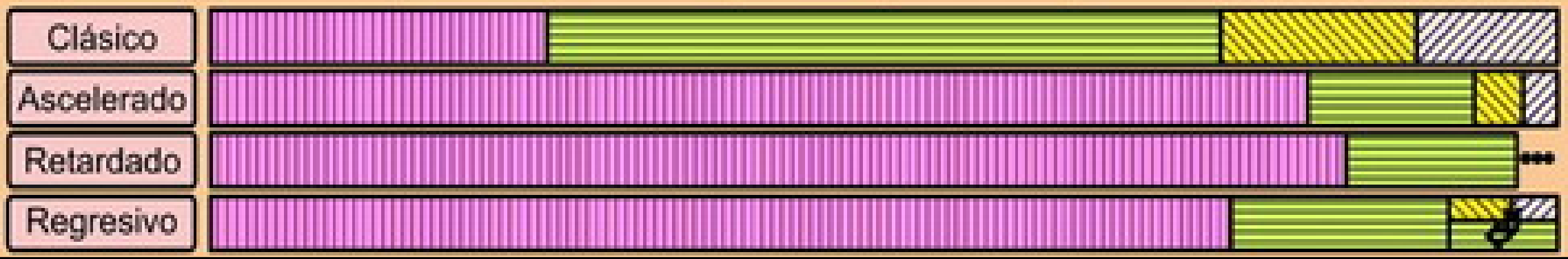

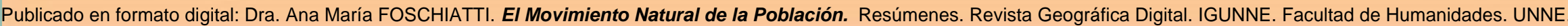
Año 8. No 16. Julio - Diciembre 2011. Resistencia, Chaco. En: http://hum.unne.edu.ar/revistas/geoweb/default.htm 